\title{
O mundo real é um lugar estranho. Notas merleau-pontyanas
}

\author{
Luís António Umbelino \\ Universidade de Coimbra (Portugal) \\ lumbelino@fl.uc.pt
}

A estranheza do real.

Nos quadros de Cézanne Merleau-Ponty (1996: 28) reconheceu dito em pintura um mundo «primordial» que, quase insuportável na sua verdade, quase intolerável na sua estranheza original, interpela incessantemente o olhar:

[...] as suas personagens-escreve o filósofo em Le doute de Cézannesão estranhas e como que vistas por um ser de uma outra espécie. A própria natureza está despojada dos atributos que a preparam para comunhões animistas: a paisagem não tem vento, a água do lago d>Annecy não se move, os objectos gelados hesitantes como no momento da origem da terra. É um mundo sem familiaridade, onde não se está bem, que interdita toda a efusão humana.

Dir-se-ia que o pintor dá conta de um mundo irreal; na verdade, é o contrário: do que se trata é de interrogar em pintura o real mais extremo e radical, aquele que, justamente, parece albergar um poder de irrealidade quase ficcional.

Cézanne investiga assim o lado perigoso e perturbador da interrogação sobre o real: aquele lado que nos obriga a 
pôr em causa o que nos habituámos a pensar que existe necessariamente e é indestrutível, sejam os objectos que construímos e usamos, as ruas e as cidades que planificamos, ou os significados definitivos que nos dão a segurança para manipular o que julgamos familiar. De facto, e nisto não estará um dos seus méritos menores, a «pintura de Cézanne põe em suspenso estes hábitos e revela o fundo de natureza inumana no qual o homem se instala» (Merleau-Ponty, 1966: 28). E, ao fazê-lo, precisamente, demonstra-nos que a verdadeira interrogação sobre o 〈mundo real〉 é aquela que procura saber o que é o mundo antes de ser algo sobre o qual falamos e teorizamos, antes de ser algo que temos como certo, antes de o enquadrarmos por um conjunto de significados instrumentais.

Que seja na 〈fidelidade aos fenómenos〉 de um olhar capaz de ir «até às raízes, para além de toda a humanidade constituída» (Merleau-Ponty, 1966: 28), capaz de se sentir germinar com a paisagem e se incrustar na «vibração das aparências que é o berço das coisas» (Merleau-Ponty, 1966: 30), que tal interrogação se mantém aberta, merece igualmente atenção: sustenta-se, deste modo, que o mundo real que se demanda é, de algum modo, o mundo percebido.

Poderia dizer-se, então, que o pintor descobre o que a mais recente fenomenologia deveria formular: que «o mundo está já sempre aí, antes da reflexão, como uma presença inalienável»; que o último a procurar não é a essência do mundo traduzida no que o mundo é em ideia, mas a realidade do mundo tal como ela se desvenda em e através de um «comprometimento efectivo»-corporal, portanto- de um sujeito incarnado; que, enfim, imanência e transcendência coexistem e se entrecruzam imemorialmente, obrigando a reconhecer que o real é, primitivamente, o que se manifesta nessa coexis- 
tência e entrecruzamento -ou, dito de forma mais específica, que o mundo real é o mundo fenomenal (Dilon, 1988: 90).

O primado do fenomenal e a motricidade corporal.

A ser verdade o que ensina o pintor, enganam-se então todos os dualismos da tradição, enclausurados que permanecem num ilusório pressuposto de adequação e na presunção de um ‘em si inabalável e exclusivo: o mundo constituído para o empirismo, ou o sujeito constituinte para o intelectualismo. Segundo Merleau-Ponty, assim polarizados e excludentes, tais estrabismos permanecem cegos para o tecido fenomenal do mundo real: o «empirismo não percebe que precisamos de conhecer o que procuramos, pois de outro modo não o procuraríamos, e o intelectualismo não consegue compreender que precisamos se ser ignorantes do que estamos á procura, ou do mesmo modo, uma vez mais, não deveríamos procurá-lo» (Merleau-Ponty, 1945: 36). Ignoram, portanto, por igual, que ao nível concreto e originário da experiência perceptiva vivida, tal como o pintor a exerce em acto, não é possível traçar separações entre sujeito e objecto, interior e exterior, imanência e transcendência, pertença e significação. O que existe e é real será esse <espectáculo〉 do qual fazemos parte tantas vezes 〈sem o ver〉 e que o pintor tenta fixar nos seus quadros.

Para pintar uma paisagem, por exemplo, Cézanne informava-se sobre suas as bases geológicas, procurava um lugar de onde ver e depois «não mexia mais e olhava), com os olhos dilatados, como dizia a sua mulher, com o corpo todo feito olhar - um olhar que parecia 〈germinar〉 com a paisagem (Merleau-Ponty, 1966: 29). Era, então necessário soldar uns aos outros todos os olhares possíveis sobre aquele motivo, reunir o que a versatilidade dos olhos tende a dispersar, 
«juntar as mãos errantes da natureza», saturar a paisagem de toda a sua intensidade errante e assim encher esse «minuto do mundo que passa» para o poder pintar «na sua realidade». Atacava então a tela por todos os lados: «a imagem saturava-se, ligava-se, desenhava-se, equilibrava-se, e ao mesmo tempo vinha a maturidade. A paisagem, dizia, pensa-se em mim e eu sou a sua consciência» (Merleau-Ponty, 1966: 30). Nesta medida, os seus quadros não são uma cópia ou imitação da superfície das coisas: eles dão-nos as próprias coisas na sua origem, ou talvez melhor, «a vibração das aparências que é o berço das coisas» (Merleau-Ponty, 1966: 30). O trabalho incessante de Cézanne é o de converter em coisa visível o que sem um olhar que vai até ás raízes, jamais chegaria à expressão do seu próprio sentido. Assim, o pintor demonstra em acto que é por ser corpo-no-mundo que o sujeito pode contribuir para o aparecer do mundo. Dito de outro modo, há que notar que é por, enquanto corpo, o seu modo de «ir até ao mundo» ser já também um «ir no mundo» que o sujeito perceptivo se pode entender como «condição» - enigmaticamente já sempre condicionada - do aparecer do mundo. E nesta medida se dirá que é arqueologicamente «real» o que do mundo se inscreve numa «certa atitude do corpo» - de um corpo vivido que, finalmente, deverá afirmar-se «saber mais do que nós sobre o mundo, sobre os motivos e os meios com que se tem que fazer a sua síntese» (Merleau-Ponty, 1945: 276).

De facto, no corpo misturam-se e articulam-se os modos fundamentais de pertença ao mundo e de fenomenalização, sendo que tais modos não derivam da reflexividade de uma consciência expressa, mas antes, justamente, de um comprometimento ou conivência activa capaz de desenrolar (por incorporação) significados práticos. $\mathrm{O}$ mesmo é dizer que o 
percepcionado é, de facto, o primitivamente dado como relativo a uma atitude motora havendo que concluir que a motricidade é a intencionalidade originária (Merleau-Ponty, 1945: 160), ou o que é o mesmo, que a consciência, no seu nível fundacional (e sobre este nível se fundarão os seus restantes modos), é uma praktognosia (Merleau-Ponty, 1945: 164). Num certo sentido, tal implica reconhecer que o mundo (real enquanto fenómeno corporalizado) não «fala» primeiro ao nosso entendimento reflexivo e temático, mas a um sujeito da percepção que deve reconhecer-se em exercício "por debaixo» (no sentido em que é ontologicamente anterior) do sujeito pessoal. A percepção, na sua origem, não é algo que um «eu» constituído faça, ou lhe aconteça. A percepção, assim enraizada na motricidade, é pré-pessoal e anterior à reflexividade do cogito constituído. O seu traço distintivo será, originariamente, o anonimato, pelo que do mundo se deveria começar por dizer que «se percebe em mim e não que eu percebo» (Merleau-Ponty, 1945: 249).

Esta afirmação é tão importante quanto problemática. Desde logo, por apontar a uma sombra de impensado no próprio interior da análise fenomenológica de Merleau-Ponty. De facto, que algo se perceba em mim e não que «eu» perceba -ou seja, que antes da consciência reflexiva se constituir, o corpo que sou seja já o lugar onde as coisas do mundo vêm à procura do seu próprio sentido- obriga a reconhecer uma tensão incontornável no centro de uma investigação fenomenológica que reconhece na percepção uma chave do fenomenal. Tal tensão desenha-se entre, por um lado, a ideia fenomenológica de consciência -como sendo sempre consciência de alguma coisa- e, por outro, o facto evidente de tal consciência ser intencional apenas na medida em que, enquanto essencialmente incarnada (logo, marcada pela passividade e pela opaci- 
dade) e, portanto, mundana ser originariamente convocada, atravessada, descentrada, embargada, excedida por aquilo de que é consciência. Pela orientação daquele primado da consciência, o percebido tenderá a ser entendido directamente como todo o ser percebido; mas, pela evidência do descentramento e da não-coincidência, do anonimato e do irreflectido que parecem marcar a experiência perceptiva enraizada na motricidade corporal, no entanto, torna-se progressivamente evidente que o ser percebido não só não se reduz ao percebido como parece ser o facto de em muito o extravasar que permite que algo se perceba.

Ante tal tensão não espanta que Merleau-Ponty reconheça rapidamente a necessidade de radicalizar -de explicitar ontologicamente- os resultados da sua fenomenologia da percepção (Merleau-Ponty, 1964b: 237) no sentido da investigação renovada de um ser percebido que apenas no excesso por relação à percepção com ela parece pactuar arcaicamente. Ainda na Phénoménologie, Merleau-Ponty parece já intuir o caminho a seguir ao referir à necessidade de investigar a «camada primordial na qual nascem as ideias e as coisas» (Merleau-Ponty, 1945: 254), camada que o pintor já pressentia - por um incontornável «sentimento de estranheza» (Mereleau-Ponty, 1966: 30) - numa paisagem que aparece sempre nova em cada olhar, que interpela como aceno de um fundo de profundidade. A questão será bem a de saber a que corresponde tal «camada primordial» e de que modo se pode pensar inteiramente o que sustenta a significativa promiscuidade (Saint Aubert, 2006: 11-35) do corpo e do mundo que assim se anuncia. 
A carne do real: loucura da visão, simulacros errantes e espectros.

Para o pintor, recorde-se, a essa camada primordial se votava um olhar capaz de ir "para além de toda a humanidade constituída». Esse olhar selvagem é aquele que uma paisagem, um utensílio, um rosto subitamente podem sobrevir como ícone vivido de um mundo mudo, vertical, em bruto. Falamos aqui desses momentos em que um olhar dilatado percebe subitamente certos objectos, lugares ou paisagens -no momento de transgredirem o peso da sua história, do seu uso, da cultura e das ideias aceites, no momento de excederem a sua materialidade- afastarem-se da sua mera presença e fazerem-se guia de algo essencial, mas não domesticável, «por exprimir». Mas o quê, exactamente? Esta questão pressentese plenamente sob as análises de L`oeil et l>esprit -texto contemporâneo do projecto de Le visible et linvisible-, nas quais Merleau-Ponty se refere ainda, significativamente, a esse «olhar pré-humano» que é o «emblema» do pintor (MerleauPonty, 1964a: 32). Escusado explicitar que tal «ver» nunca se poderia reduzir a um «pensamento de ver». O seu campo é a ambiguidade e o equívoco, a opacidade e a profundidade. Mais: nele se resume um enigmático modo de apagamento da centralidade do sujeito e se esboça uma espécie de «intencionalidade latente» que é integralmente um ser em. Este ser em de um «sujeito» apagado será outro modo de dizer um olhar que é assombração do visível. Mas se o olhar de que falamos é um modo de assombrar o visível não é senão porque o próprio visível, no seu excesso inumano, ou seja, naquilo que transborda em ausência qualquer mundo perceptivo, já veio assombrar imemorialmente esse mesmo olhar sob a forma de uma interpelação incessante em vazio. Nesta me- 
dida, para «ver» é realmente preciso, como escreve MerleauPonty, que «com o meu corpo desperte os corpos associados, os 〈outros〉 (...) que me assombram, que eu assombro» (Merleau-Ponty, 1964a: 13); é preciso que desperte os «simulacros errantes», os «espectros», que Descartes pretendia exorcizar na sua fuga à ambiguidade; estes, na verdade, são revelações da própria estrutura transcendental do que significa pertencer a um visível cruzado de invisível ${ }^{1}$.

Tal modo de pertença reveste a forma de um «estranho sistema de trocas», (Merleau-Ponty, 1964a: 21) que se poderia dizer uma forma de «imbricamento», de «entrelaçamento» (quiasmático); tal forma, por um lado, obriga a recusar a ideia de uma exterioridade do vidente em relação ao visível e, concomitantemente, compele a interrogar o que faz e sustenta tal enlace. $\mathrm{O}$ modo como Merleau-Ponty ensaia uma resposta a esta questão pode ser ilustrado, de forma paradigmática, pela forma como retoma (radicalizando a interpretação da Phénoménologie) a experiência do corpo «tocantetocado» a partir de uma reflexividade mais fundamental: a do próprio sensível. No contexto da reflexão ontológica esboçada em Le visible et linvisible, os ensinamentos da reversibilidade táctil do corpo tocante-tocado - que encontra um paralelo no caso da visão entendida como «palpação pelo olhar» (Merleau-Ponty, 1964: 176) - sugerem mais do que a simples relação entre tocar e sentir-se tocado, entre ser activo e sentir-se passivo: sugerem que quando, a partir do meio do mundo, o tocante se toca, o tocado se desvenda tangibilidade

1 E se a pintura de Cézanne o ilustra bem, será, justamente por misturar «todas as nossa categorias, ao desenrolar o seu universo onírico de essências carnais, de semelhanças eficazes de significações mudas» (Merleau-Ponty, 1964a: 35), senão porque, enfim, mostra escondendo que «ver é sempre ver mais do que aquilo que vemos» (Merleau-Ponty, 1964b: 300). 
partilhada com tudo o que é tangível - do mesmo modo que quando o vidente vê, palpa uma visibilidade que, parecendo «sua», na verdade se estende e desdobra em uma visibibilidade partilhada que extravasa em muito o que se pode ver. Nessa reversibilidade, o tocante que é parte da tangibilidade, o vidente que é parte da visibilidade não se encontrarão no regresso a qualquer imanência subjectiva; a reversibilidade é realmente do visível e do tangível e só por isso o corpo é tocante-tocado e vidente-visível. Numa passagem importante e bela de L〉oeil et l>esprit, Merleau-Ponty resume assim o essencial: «um corpo humano está aí quando entre vidente e visível, entre tocante e tocado, entre um olho e outro, entre a mão e a mão se faz uma espécie de recruzamento, quando se acende a centelha do sentiente-sensível, quando se toma esse fogo que não cessa de arder» (Merleau-Ponty, 1964a: 3). Dito de outro modo, dir-se-ia que a carne do corpo contacta com algo mais do que a sua massa, com algo de que a sua carne é feita mas com a qual não coincide, algo em que participa sem saber onde começa ou acaba -algo como a própria Carne do mundo.

Deste modo se esboça uma necessária viragem anti-antropocêntrica da análise no sentido de uma nova concepção de Ser: de um Ser «polimórfico» de «indivisão», vertical, de um Ser de dimensionalidade, coesão e envolvimento. Mas do que se trata aqui de pensar com estes termos? Para concretizarmos o que vem sendo dito, ajuda-nos o facto de MerleauPonty considerar que tal nova concepção de Ser é anunciada por várias propostas científicas modernas. Confirma-o, por exemplo, a etologia e, nomeadamente, as importantes investigações de Uexküll sobre o Umwelt dos animais (MerleauPonty, 1994: 270 ss; Uexküll s/d: 23 ss; Buchanan, 2008: 115 ss.). Nestes trabalhos interessará primeiro a Merleau-Ponty 
a demonstração de que o Umwelt do animal é um ambiente fechado, com «significados biológicos próprios» para o comportamento animal e que desenrola um tempo e um espaço próprios. Não há, pois, um mundo único para todos os animais, mas uma multiplicidade de mundos ambientes, que são outros tantos «mundos próprios» dificilmente configuráveis pela perspectiva humana. O Umgebund do animal humano é, analogamente, um ambiente fechado e, embora nele se percepcionem os mundos ambientes que se desenrolam em redor dos animais, o modo próprio como um animal se relaciona com o seu meio não é, em si, concebível antropocentricamente. Mais, esses mundos ambientes existem como tal e são reais independentemente do que se passa no mundo perceptivo humano.

Em segundo lugar, interessa a Merleau-Ponty a demonstração de que entre o comportamento significativo de um animal e o significado externo daquilo que o meio ambiente lhe oferece como «marca» não existe uma relação de estímulo-resposta, mas algo como uma estreita unidade funcional, que se assemelha a uma unidade musical. $\mathrm{O}$ modo de ser do organismo como um «ser-no-mundo» é o próprio cruzamento é pelo interior do Umwelt, tanto quanto a realidade do Umwelt nunca aparece como algo de exterior ao modo de cruzamento e de imbricamento do corpo animal; dir-seia, de facto, que se encontram unidos formando algo como uma melodia, ou seja, incarnando uma unidade harmoniosa como as respectivas notas. É o caso da aranha e da mosca, da carraça e do cão. Embora vivendo em mundos perceptivos distintos e que nada sabem um do outro, a aranha constrói a sua teia à medida das dimensões e força da mosca; embora nada sabendo do mundo ambiente do cão, a carraça pode esperar meses sobre uma folha até saltar para o cão que passa perto com a temperatura corporal «certa». 
A Merleau-Ponty interessa aqui a possibilidade de pensar algo como a incarnação de um Todo englobante e coeso que, no entanto, permanece inacessível a todos os mundospróprios: um Todo englobante que permanece como o que sustenta mas nunca se faz integralmente presente. Falar de «melodia», de facto, equivale a dizer, por um lado, que o respectivo tema ou «totalidade governando as realizações, está presente e, por outro, que a totalidade para a qual os eventos se referem está ausente» (Barbaras, 2004: 227) - ou talvez melhor: está presente na sua própria aparição como ausência, lacuna, recuo ou desvio interno em relação a si própria. Tal não significa sugerir aqui a ingerência de uma realidade superior, a presença de uma «essência fora do tempo» (Merleau-Ponty, 1994: 285), de «uma coisa supra-sensível» (Merleau-Ponty, 1994: 289), ou de uma presença panteísta. O que surge decisivo a Merleau-Ponty nas investigações de Uexküll é a demonstração de uma dimensionalidade recíproca, de uma «coesão sem conceito», de uma participação comum na textura partilhada de envolvimento que sustenta todos os «mundos próprios» mas que nenhum pode exaurir. Por isto, o essencial da análise do Umwelt, para Merleau-Ponty, será «uma teoria da carne» (Merleau-Ponty, 1994: 271) na medida em que tal análise obriga «a ligar o que normalmente separamos» (Merleau-Ponty, 1994: 228). Mas obriga também a sustentar que aquilo que liga nunca se presentificará integralmente, nunca será uma positividade, antes permanecendo anúncio (ou a «marca») invisível do que suporta e, de algum modo, faz, nomeadamente, o mundo percpetivo.

Assim se perceberá que o gesto de explicitação ontológica desenvolvida por Merleau-Ponty se oriente para ultrapassar radicalmente uma «filosofia da coisa positiva», na direcção uma filosofia que parte de algo já sempre aí, de um ser «bruto» 
ou «selvagem» que não se coloca vencendo o nada (e portanto nega o princípio da razão suficiente), mas que também não é uma pura presença definível por identificação a si e com a qual o vidente coincidiria num qualquer tipo de monismo. Outrossim, no centro do Ser de que nos fala Merleau-Ponty prevalece uma presentificação em vazio (não positivo), uma lacuna que consubstancia o intocável e o invisível como dimensões intrínsecas desse médium sensível pelo qual pode haver o ser sem que o ser seja positivamente dado (MerleauPonty, 1964: 267). A «natureza na sua origem», a natureza inumana que Cézanne investigou, é essa carne (quiasmática) do real, essa invisibilidade de envolvimento, esse «elemento» ou «espécie de princípio incarnado que importa um estilo de ser por todo o lado onde se encontra uma parcela» (Merleau-Ponty, 1964: 184), esse «elemento» que «não é nunca o que está à frente, mas o que nos contém» (Merleau-Ponty, 1994: 20); o que nos contém como uma «melodia que se canta a si própria», como uma totalidade englobante que «canta em nós muito mais do que nós a cantamos» (Merleau-Ponty, 1994: 228), como um aceno inumano sempre irredutível a qualquer subsunção antropocêntrica.

Neste contexto, o invisível de que nos fala Merleau-Ponty «não é apenas não-visível (o que foi ou será visto e não o é, o que foi visto por outro e não por mim)», mas «ausência que conta no mundo», Urpräsentiert que se mantém Nichturpräsentierbar (Merleau-Ponty, 1964: 281). Esta negatividade, ausência, lacuna ou invisibilidade não se opõe ao visível, já que se trata de algo que permanece interior ao Ser; algo que marca uma dupla distância: da totalidade do Visível por relação a si e, concomitantemente, do vidente por relação à transcendência que assim se esboça no interior do Ser. No entanto, é esse mesmo Visível que destila uma invisibilidade 
que o olhar -do pintor, pelo menos- acolhe. Tal acolhimento, no entanto, não pode ser agora entendido senão como uma «redução de afastamento» e «afastamento mantido» (Merleau-Ponty, 1994. 284). Se é verdade que o Ser contém também a sua própria negação o seu «percipi» (Merleau-Ponty, 1964: 304) será este que fundará o percipere. O que não é dizer pouco: só nos «aproximamos» do real mantendo a distância interior que nele subsiste, ou seja, acompanhando o que inquieta, a lacuna, o «entre», o que diverge, a ausência em cada presença - enfim, desejando o que falta e faz falta.

Porventura será esta vocação desejante o saber originário do olhar - do olhar alienado, delirante, enlouquecido que é o único capaz de acolher a vibração da «natureza primordial», dessa Natureza que atravessa o nosso mundo perceptivo mas permanece na sua totalidade para lá dele, que o sustenta mas o assombra de todos os outros mundos possíveis. Desse olhar parece a pintura guardar o segredo mais profundo. Merleau-Ponty quer convencer-nos disso ao escrever: «a pintura [...] leva à sua derradeira potência um delírio que é a própria visão, porque ver é ter à distância, e a pintura estende esta bizarra posse a todos os aspectos do Ser, que devem de qualquer modo tornar-se visíveis para entrar nela» (MerleauPonty, 1964a: 27).

\section{Bibliografía}

Barbaras, R. (2008). Introduction à une phénoménologie de la vie. Paris: Vrin.

2 No sentido em que Barbaras utiliza este termo (Barbaras, 1999; Barbaras 2004) e Merleau-Ponty parece intuir nas notas de aula sobre dedicadas ao conceito de Natureza (Merleau-Ponty, 1994: 287). 
Barbaras, R. (2004). A Phenomenology of Life, em Carmen, $\mathrm{T} \&$ Hansen, M. (eds.). The Cambridge Companion to Merleau-Ponty. Cambridge: University Press.

Barbaras, R. (1999). Le désir et la distance. Introduction à une philosophie de la perception. Paris : Vrin.

Buchanan, B. (2008). Onto-Ethologies. The Animal Environments of Uexküll, Heidegger, Merleau-Ponty, and Deleuze. New York: State University of New York Press.

Dilon, M. C. (1988). Merleau-Ponty>s Ontology. Bloomington and Indianapolis: Indiana University Press.

Merleau-Ponty, M. (1994). La Nature. Notes de cours du Collège de France. Paris: Seuil.

Merleau-Ponty, M. (1966). Le doute de Cézanne (1945), em Merleau-Ponty, M. Sens et non sens. Paris: Nagel.

Merleau-Ponty, M. (1964a). L'oeil et l'esprit. Paris: Gallimard, Paris.

Merleau-Ponty, M. (1964b). Le visible et l'invisible. Paris: Gallimard.

Merleau-Ponty, M. (1945). Phénoménologie de la perception. Paris: Gallimard.

Saint Aubert, E. (2006). La 〈promiscuité〉. Merleau-Ponty à la recherche d sune psychanalyse ontologique, em Archives de philosophie, t. 69, 11-35.

Uexküll, Jakob von (s/d). Dos Animais e dos Homens, A. Candeias e A. pereira (trad.). Lisboa: Livros do Brasil. 


\section{Resumo}

No presente trabalho pretendemos meditar sobre a tese de Merleau-Ponty segundo a qual o mundo fenomenal é o mundo real e estudar algumas das respectivas implicações fenomenológicas e ontológicas. Como introdução, mostraremos que a estranheza do mundo primordial de que o pintor dá notícia nos indica o caminho de investigação do fenomenal; depois, trataremos de clarificar o aspecto propriamente fenomenológico do primado do fenomenal em Merleau-Ponty; num terceiro momento estudaremos os traços mais decisivos do necessário aprofundamento ontológico das teses fenomenológicas avançadas; e terminaremos regressando à estranheza dos espectros e invisibilidades do ser do real merleaupontyano.

Palavras-chave: real, corpo, mundo, invisível.

\section{Abstract}

In this paper we aim to meditate on Merleau-Ponty>s thesis that phenomenal world is the real word and to address some of its main phenomenological and ontological implications. As an introduction, we begin by showing de strangeness of the «primordial word» as seen by the painter; then we will try to clarify the phenomenological aspect of the primacy of the phenomenal as «made» of that strangeness; in an another moment we will try to study the ontological radicalization of that phenomenological approach; and finally we return to the strangeness of spectres, and invisibilities of MerleauPonty>s real being.

Key-words: real, body, world, invisible. 
